\section{SIGNIFICANCE OF HYDROCARBON OILS IN CHEMICAL INDUSTRY}

\begin{abstract}
7HE Cantor Lectures on "Organic Chemicals from Petroleum", which Sir Frank Smith delivered before the Royal Society of Arts during April, were happily timed to provide the background for wide appreciation of the importance of the recommendations of the Report of the Hydrocarbon Oil Duties Committee*, which Sir John Anderson stated in his Budget speech on April 24 he proposed to accept. The Committee, over which Sir Amos Ayre presided, was appointed by the Chancellor of the Exchequer and the Minister of Fuel and Power, as indicated in last year's Budget speech, and Sir John Anderson has now included in the Finance Bill a provision freeing from Customs duty imported hydrocarbon oils used as raw materials for chemical synthesis. Provision is also to be made for an allowance of an amount equal to the Customs duty in respect of indigenous oils used in these processes, in order that the competitive position in respect of home-produced materials should not be worsened by this change.
\end{abstract}

The Ayre Committee was appointed at the end of July 1944 "to consider and report upon: (a) the effect of the hydrocarbon oil duties on the supply of raw materials to, and the development of, the chemical industry in this country so far as the use of hydrocarbons and their derivatives is concerned; and (b) the extent to which any change in those duties would affect industries engaged in the production of similar products from coal". "Chemical industry" in these terms of reference includes the producers of transformation products, such as dyes, pharmaceuticals and plastics, but excludes the industries using hydrocarbon oils as solvents only, though reference is made to the solvent-user position. Similarly, it excludes the industries concerned with the production of synthetic motor fuels and lubricants, although the Committee considered the influence of developments in this field on other modern synthetic chemical processes.

Reviewing first the effect of the duties on the chemical industry in this sense and its development, the Committee points out that while the visible direct effect of the hydrocarbon oil duties has not hitherto been large, apart from the use of petroleum oils for the manufacture of such products as wetting-agents and detergents, and of turpentine for the manufacture of so-called 'synthetic' camphor, the indirect effect has been considerable. This repercussive effect is due to the protection of indigenous oils and to the fact that benzole, one of the main hydrocarbon raw materials of the existing chemical industry, is in demand as a blending constituent, owing to its high anti-knock value, in the motor-fuel industry, where its value is regulated by that of imported duty-paid spirit. The annual cost to the chemical industry, on its pre-war consumption of 10 million gallons, which may well be exceeded after the War, is thus about $£ 375,000$ or about $\mathrm{l} d$. per $\mathrm{lb}$. on benzole.

The consequent effect on the cost of chemicals derived from benzole depends on the yield and on the number of steps in the chemical synthesis, and may be more or less than $1 d$. per $\mathrm{lb}$. on the primary intermediates. Even where the effect is less on products further removed from benzole, for example, $0.2 d$. on some finished dyes, the increase is significant

* Cmd. 6615. H.M. Stationery Office. April 1945. $3 d$. net. and often sorious in the export market. The Committee received evidence of the curtailment of the output of certain dye intermediates owing to the almost complete loss of the export trade rasulting from this position.

Morejver, as the report notes, the organic chemical industry stands at the opening of a period of great expansion. Chemicals are increasingly providing the basic raw materials of major industries such as synthetic textiles, synthetic rubber and plastics. Since Britain possesses neither the large supplies of hydrocarbons which exist, for oxample, in America, in the form of natural petroleum, nor the large numbers of scientific and technical personnel trained and experienced in development work, a great effort will be called for to enable her to play a considerable part in the new industry. It is accordingly imperative that the basic and intermediate raw materials should be made abundantly available and that the industry should be free to choose the best material for each particular process or synthesis, guided only by scientific and technical considerations. Since many of the new processes utilize materials derived in part from oil and in part from coal, the growth of the chemical industry based on petroleum may also increase the demand for raw materials derived from coal, and effect of the duties may be far greater in the future, as they will tend to stifle the large-scale production of the primary and basic intermediates.

For these reasons the Committee unhesitatingly accepts the claim that the chemical industry should be able to choose its hydrocarbon raw materials free from the direct and repercussive effects of the present hydrocarbon oil duties, and the industry takes the view that it is urgently necessary that it should be relieved of this encumbrance. The Committee was also impressed by evidence of the extensive use made of the solvent properties of hydrocarbon oils in extraction processes in the industry, while its conclusion is reinforced by its survey of petroleum as a source of chemical raw materials. While the duty on heavy oil has not had any clearly recognizable effect on such developments, the duty at $9 d$. a gallon on light oil has, and there is real danger that if the present position is maintained certain lines of development may be entirely suppressed. For example, the development of 'specialty' refining to provide the gaseous hydrocarbons, particularly the olefins containing one to four atoms of carbon in the molecule, which are the most important raw materials of the new industry, by cracking selected fractions of petroleum oils, and, by the use of aromatization processes, benzene and other aromatic hydrocarbons, will depend largely on the fiscal position. All witnesses from the oil industry urged that hydrocarbons used in the production of chemicals should be freed from duty in order that development should follow the soundest lines without being subject to artificial diversion.

A further consideration which greatly impressed the Committee was that the free growth of new industries producing and using the hydrocarbon raw materials would result in the development of new alloys, apparatus, equipment and technique which will benefit industry generally. Equally, a field would thus be provided for training chemical engineers and metallurgists, the benefit of whose experience is likely to be widely felt in many industries. The question of home refining involves considerations which lie far outside the Committee's terms of reference; but since the quantity of oil required by the chemical industry 
is very small in proportion to total oil requirements, there is, as the Committee points out, no reason why home-produced oil should not play its due part in the new developments, provided the manufacturer is free to use, unaffected by duties or their repercussions, the material most suitable for his purpose.

It is, of course, to this section of the report that Sir Frank Smith's lectures are most relevant, and the importance of the matter is well shown by some of the figures quoted by Sir Frank Smith. To-day, he said, some two hundred chemicals are made on the commercial scale from petroloum raw materials, the annual value of which he estimated at about $£ 200$ millions, and in the plastics industry the ratio of petroloum derivatives to non-petroleum derivatives as raw materials is steadily increasing. By cracking processes there are already produced 60,000 tons of ethylene for the plastics industry and 120,000 tons for ethyl aleohol. The actual volume of refinery gases in the world is about 300,000 million eubic feet per annum or 15 million tons, and acetylene is already being made from petroleum and production may be on a very large scale in the future.

Sir Frank Smith contended that there is no antagonism between the coal-chemical industry and a petroleum-chemical industry, and this contention is borne out by the third section of the Ayre Committee report, dealing with coal as a source of chemical raw materials. Surveying first the low-temperature and high-temperature carbonization processes, the Committee concludes that the producer of indigenous hydrocarbons cannot and should not be called upon to bear the cost of reduction in price of his products to the chemical industry, notwithstanding that the protection affordod in 1938 to encourage the production from indigenous materials of fuels for the internal combustion engine had raised the price of certain raw materials to the chemical industry. Considering next the three chief processes for treating coal which yield raw materials for the organic chemical industry-hydrogenation, the Fischer Tropsch process for hydrocarbon synthesis (which has not yet been operated in Britain), and the production of calcium carbide - the Committee finds it difficult to forecast the part which these processes will play in the development of the chemical industry, but believes that it will not be large in the immediate future, and that its recommendations will not impede their development.

The Committee recommends accordingly that chemical manufacturers be allowed to receive without payment of duty (or upon drawback), as raw material for chemical synthesis, any imported hydrocarbon oil, and the Chancellor of the Exchequer, as already noted, indicated his intention of amending appropriately Section 2 of the Finance Act, 1934. In respect of hydrocarbon oils produced from indigenous material and received by a chemical manufacturer as raw material for chemical synthesis, the Committee recommends payment to the manufacturer of an allowance equal to the duty payable on the importation of like oils. Similarly, any producer or refiner of indigenous oils who uses such oils for the production of hydrocarbons for use in the refinery as raw materials in chemical synthesis should also receive an allowance equal to the duty payable in the importation of like oils. On the basis of the pre-war consumption of indigenous hydrocarbon oils by the chemical industry, the total cost of implementing the Committee's recommendations is estimated at somothing less than $£ 400,000$ a year.
In announcing his acceptance of these recommendations, the Chancellor said that many believe that synthetic chemical processes will be of rapidly growing importance in manufacture, and will affect industries outside the field of synthetic chemistry. Research on these problems has been active in several countries during the last five years, and he said he hoped that the gift he was able to make towards the cost of research by this concession will help Britain to establish itself quickly in a worthy position in relation to these new developments. While the Ayre Report does not cover the whole field-and it may well be desirable to examine the wider question of home refining in relation to national economic policy - when read with the Cantor Lectures of Sir Frank Smith, it shows conclusively that we can no longer be content to treat oil questions only as matters of Imperial defence. Equally it endorses the argument of the Parliamentary and Scientific Committee for an adequate examination of our whole policy of the utilization of our coal resources. The prompt acceptance of the Committee's recommendations is a further indication of official recognition of the importance of scientific and industrial research, and a disposition to accord scientific and technical factors their due weight in the determination of policy.

\section{RUSSIAN PHYSICS JOURNALS}

GOR a time, when transport between the U.S.S.R. and Great Britain was very difficult, the flow of scientific journals almost stopped. Recently a fairly regular exchange has been re established. The following notes on physics journals may help those readers to whom the facilities of the London libraries are not readily accessible, but who nevertheless wish to know how physics has fared in the U.S.S.R. in recent years. On first thoughts, a knowledge of the Russian language may seem essential ; but realizing the severe difficulties of their language the Russians for more than ten years have been publishing foreign editions, in German, French or English, of some of their journals. Attention will be confined almost entirely to such journals.

The earliest journal of special interest to physicists appears to be the Physikalische Zeitschrift der Sowjetunion, published at the rate of two volumes each year starting in 1932. Although most of the papers are in German, some papers are in English. Next to be started was Technical Physics of the U.S.S.R., founded in 1934, having papers in English, German or French. By 1939 the fifth volume had been reached with a publication.rate of about twelve parts a year. The centre of publication was Leningrad. In the first volume the editor, A. Joffe, explains that before the Revolution there was practically no technical physics in Russia. By 1934 a number of institutes giving their attention to immediate problems in technical physics had been established. Joffe lists them in seven groups: (1) a group of physical-technical institutes including four Leningrad institutes, Kharkov, Ural, Siberia, Dniepropetrovsk and the Physical Agronomical Institute -with one thousand workers; (2) the Optical Institute-with four hundred workers ; (3) the AllUnion Electro-Technical Institute with one thousand workers; (4), the Power and Thermal Institutes; (5) the Central Radio Laboratory ; (6) the Metallurg- 